\section{$\underset{\substack{\text { hommes } \\ \text { \& migrations }}}{ }$}

\section{Hommes \& migrations}

Revue française de référence sur les dynamiques

migratoires

$1306 \mid 2014$

Ecriture et migration

\title{
Shumona Sinha, Calcutta
}

Paris, L'Olivier, 2014, 206 pages, $18 €$.

\section{Élisabeth Lesne}

\section{(2) OpenEdition \\ 1 Journals}

\section{Édition électronique}

URL : http://journals.openedition.org/hommesmigrations/2832

DOI : 10.4000/hommesmigrations.2832

ISSN : 2262-3353

\section{Éditeur}

Musée national de l'histoire de l'immigration

\section{Édition imprimée}

Date de publication : 1 avril 2014

Pagination : 122-122

ISBN : 978-2-919040-27-8

ISSN : $1142-852 X$

\section{Référence électronique}

Élisabeth Lesne, «Shumona Sinha, Calcutta », Hommes \& migrations [En ligne], 1306 | 2014, mis en ligne le 06 août 2014, consulté le 22 septembre 2020. URL : http://journals.openedition.org/ hommesmigrations/2832; DOI : https://doi.org/10.4000/hommesmigrations.2832

Ce document a été généré automatiquement le 22 septembre 2020.

Tous droits réservés 


\title{
Shumona Sinha, Calcutta
}

Paris, L'Olivier, 2014, 206 pages, $18 €$.

\author{
Élisabeth Lesne
}

\section{RÉFÉRENCE}

Shumona Sinha, Calcutta,

Paris, L'Olivier, 2014, 206 pages, $18 €$.

\section{NOTE DE L'ÉDITEUR}

Sélection 2014 de la $5^{\mathrm{e}}$ édition du prix littéraire de la Porte Dorée

1 C'est à l'annonce de la mort de son père que Trisha retourne en Inde, dans sa ville natale. Après la violence de la crémation, «Il faut porter le feu jusqu'à sa bouche, jusqu'à l'origine des choses et des paroles, avant de soumettre le corps entier à la fournaise et baisser le rideau de fer", elle retrouve la maison vide de son enfance, d'abord avec un sentiment de malaise, celui d'être une intruse, et puis les souvenirs affluent : «C'est avec le rez-de-chaussée qu'elle a un lien. Là, les chambres ont retenu son souffle, les murs connaissent ses empreintes. » Lui reviennent les bruits, les odeurs, les couleurs de sa vie antérieure et des bribes de son histoire familiale au hasard des objets retrouvés : le revolver et l'attaché-case de son père, le flacon de parfum d'hibiscus de sa mère... Ses parents formaient un couple curieusement assorti. Sa mère était en proie à une "indéfinissable douleur » et sujette à des crises imprévisibles qui renvoyaient chacun à sa solitude : «Comment vivre sous la menace de mille serpents pouvant surgir à tout moment de la cendre tiède de la mélancolie? » Farouchement athée et communiste, Shankhya, son père, après avoir couché son épouse assommée par les antidépresseurs et les somnifères, " partait rejoindre ses camarades de la révolution avortée », ses jours étant constamment en danger dans les années 1970 quand la dame de fer Indira Gandhi faisait régner la terreur chez ses opposants. Pour la petite fille, rien n'était plus douloureux, plus mystérieux que l'absence de ce père 
inventif, avant-gardiste, idéaliste, qui invitait chez lui le chauffeur de pousse-pousse, le facteur, le mari de la bonne..., sa façon à lui d'abolir le système de classes. Ce savant leur parlait de la Voie lactée et d'Andromède, de l'univers, des trous noirs, alors sur le chemin du retour, le temps de quelques instants, «ils étaient arrachés au passé qui pesait sur leurs épaules comme le fardeau de Sisyphe, ils n'avaient pas tout compris mais quelque chose les avait libérés, ils étaient comme emportés par le vent du soir et ils avançaient dans le noir, croyant y voir plus clair».

2 Une très belle figure illumine encore ces pages, celle d'Annapurna, la grand-mère paternelle, dont la vie, lorsqu'elle la raconte à Trisha, évoque les contes des Mille et Une Nuits. Mère de cinq enfants, c'est de son fils Shankhya qu'elle se sent la plus proche, il y avait entre eux "comme un pacte secret, un pacte de sacrifice, de maladie, de mort. Ils veillaient l'un sur l'autre, ils veillaient ensemble la mort aussi (...) et rien ni personne ne pouvait troubler cette intimité».

3 La seule pomme de discorde entre eux : la religion ou, aux yeux du fils marxiste, " la pierre tombale de la foi sous laquelle toute pensée rationnelle et tout raisonnement scientifique étaient ensevelis depuis longtemps ». Et le récit de remonter à la présence britannique et à l'origine de la violence entre hindous et musulmans.

4 Lire Calcutta est un voyage. Dès les premières pages, on est happé par la beauté de la langue, la force des images, embarqué dans ce récit d'un retour au pays natal, où se mêlent de manière subtile les souvenirs de Trisha et l'histoire politique du BengaleOccidental. 